\title{
Mass Fractionation in Hydrodynamic Escape
}

\author{
DONALD M. HUNTEN
}

Lunar and Planetary Laboratory, University of Arizona, Tucson, Arizona 85721

\author{
ROBERT O. PEPIN
}

School of Physics and Astronomy, University of Minnesota, Minneapolis, Minnesota 55455

AND

JAMES C. G. WALKER

Space Physics Research Laboratory, University of Michigan, Ann Arbor, Michigan 48109

Received July 25, 1986; revised October 27, 1986

\begin{abstract}
We show that mass fractionation occurs during the course of hydrodynamic escape of gases from the atmosphere of an inner planet. Light gases escape more readily than heavy gases. The resultant fractionation as a function of mass yields a linear or concave downward plot in a graph of logarithm of remaining inventory against atomic mass. An episode of hydrodynamic escape early in the history of Mars could have resulted in the mass-dependent depletion of the noble gases observed in the Martian atmosphere, if Mars was initially hydrogen rich. Similarly, a hydrodynamic escape episode early in Earth's history could have yielded a mass-dependent fractionation of the xenon isotopes. The required hydrodynamic escape fluxes and total amounts of hydrogen lost from the planets in these episodes are large, but not impossibly so. The theory of the mass fractionation process is simple, but more work will be needed to put together an internally consistent scenario that reconciles a range of data from different planets. $(c) 1987$ Academic Press, Inc.
\end{abstract}

\section{INTRODUCTION}

Many data on the composition of planetary atmospheres reveal the tendency for these atmospheres to be depleted in light gases relative to a presumed primordial standard. In this paper we suggest that this kind of mass-dependent fractionation may be a consequence of the hydrodynamic escape of large amounts of hydrogen during the early evolution of the planets.

The escape of gas from a planetary atmosphere can be approximately described either by the kinetic theory of gases, in which case the escape process is called Jeans escape, or by continuum theory, in which case the process is called hydrodynamic escape. The kinetic theory approach is most convenient when escape rates are low and the transition from continuum flow to free molecular flow occurs at an altitude at which the outflow velocity is still subsonic. Large escape rates correspond to supersonic flow at levels where the mean free path between collisions is still small compared to the scale height of the atmosphere. Under these conditions the continuum theory provides the most accurate description of the escape process (Walker, 1977, 1982). Conditions on the inner planets today do not result in hydrodynamic escape, but hydrodynamic escape from these planets would have occurred if their atmospheres were ever rich in hydrogen. The low molecular weight and weak gravitational binding of hydrogen results in large escape rates from hydrogen-rich atmospheres around the relatively small inner planets.

The flux of ultraviolet radiation from the young Sun was probably considerably 
larger than this flux today (Zahnle and Walker, 1982). Enhanced ultraviolet flux could have promoted the photochemical breakdown of water vapor to hydrogen in the atmospheres of the inner planets early in the history of the Solar System. At the same time, enhanced ultraviolet fluxes would have provided the source of thermospheric energy that could have driven large hydrodynamic escape fluxes, particularly from Mars with its small gravitational field. Other possible sources of hydrogen could be reduction of $\mathrm{H}_{2} \mathrm{O}$ in the interior followed by degassing, or a remnant of solar nebular gas, gravitationally condensed to the planet (e.g., Hunten, 1979).

We are not able to assert with confidence that hydrodynamic escape occurred from the primitive planets. Such a prediction would require further theoretical study and would depend strongly on assumptions concerning the water vapor or hydrogen contents of their atmospheres. Our goal, here, is to show how hydrodynamic escape, if it took place, could have yielded the mass-dependent fractionation that has been revealed in modern measurements, particularly of inert gas concentrations. In what follows, therefore, we shall assume a value for the hydrodynamic escape flux of hydrogen, which we assume to be the major constituent of the primitive atmosphere, and shall calculate the impact of this escape flux on the abundances of heavier atmospheric constituents.

Mass fractionation in hydrodynamic escape has not been previously studied for the electrically neutral atmospheres of the planets. The process has received some attention in connection with the solar wind (Geiss et al., 1970; Joselyn and Holzer, 1978; Geiss, 1982), but the results turn out to be quite different for a highly ionized gas. For such a gas, the collision cross section is a strongly increasing function of atomic mass so that heavier atmospheric constituents diffuse less freely than light ones. The consequence is that there is little discrimination with respect to mass in the outflow process. As we shall show here, conditions are quite different in an electrically neutral gas, for which collision cross sections are approximately independent of atomic mass. Under these circumstances the hydrodynamic escape process is strongly mass selective, with light constituents being carried away from the planet and heavy constituents being left behind.

\section{EFFECT OF HYDRODYNAMIC ESCAPE ON HEAVY GASES}

A number of theoretical studies have presented profiles of density, velocity, and temperature in an atmosphere undergoing hydrodynamic escape from an inner planet (Hunten, 1979; Watson et al., 1981; Kasting and Pollack, 1983). Expansion of the outflowing gas keeps temperatures low, even when the rates of supply of energy to the thermosphere are large. The temperature typically rises to a maximum of a few hundred degrees Kelvin at the level of maximum energy input and then falls off gradually to zero (or a very small value) at very great distances from the planet. This temperature variation has an important effect on the hydrodynamic escape flux of major atmospheric constituents but has little impact on the density or velocity profiles of heavy, minor atmospheric constituents. For simplicity we shall deal with isothermal atmospheres in our treatment of the heavy gases. Temperature gradients can in fact be accommodated without difficulty (Hunten, 1973). Inclusion of eddy diffusion also makes very little difference, because the rapid escape itself tends to nullify diffusive separation and to yield a composition independent of height.

The outflow velocity in a hydrodynamically escaping atmosphere is small at low altitudes where ambient densities are high. The velocity increases with altitude so as to preserve continuity of the escape flux, but the rate of increase of velocity with altitude decreases with increasing altitude. The velocity gradient is small at high altitudes. The ambient density closely follows the barometric equation at low altitudes where acceleration terms in the equation of mo- 
mentum balance are small. The acceleration terms become important at high altitudes where flow velocities are supersonic. These nonlinear terms have an important influence on the hydrodynamic escape flux of the major constituents of the atmosphere, but they are not likely to greatly affect the escape fluxes of the heavy, minor atmospheric constituents that we shall be calculating here. The fluxes of constituents with molecular masses much greater than the molecular mass of the ambient atmosphere are determined by diffusion processes occurring at relatively low altitudes where outflow velocities are subsonic. Once the fluxes are established, they must obey the continuity equation, which is highly restrictive if the flow is spherically symmetric. These rather intuitive arguments are essentially confirmed by a numerical study by Zahnle and Kasting (1986).

Consider an atmosphere composed of two constituents of masses $m_{1}$ and $m_{2}$, number densities $n_{1}$ and $n_{2}$, and vertical velocities relative to the planet of $w_{1}$ and $w_{2}$. Acceleration terms in the equations of motion of these gases can be neglected provided there is little change in mean velocity during the time between collisions. In this case the relative velocities are determined by diffusion processes

$$
\begin{aligned}
& w_{1}-w_{2}=-\frac{b}{n_{2}}\left[\frac{1}{n_{1}} \frac{d n_{1}}{d r}+\frac{m_{1} g}{k T}\right] \\
& w_{2}-w_{1}=-\frac{b}{n_{1}}\left[\frac{1}{n_{2}} \frac{d n_{2}}{d r}+\frac{m_{2} g}{k T}\right]
\end{aligned}
$$

(Chapman and Cowling, 1970; Hunten, 1973, 1985; Walker, 1977, 1982) where $b$ is the diffusion parameter (the product of diffusion coefficient and total number density), $g$ is the acceleration due to gravity, $k$ is Boltzmann's constant, and $T$ is absolute temperature. These equations can be rearranged to give expressions for the density gradients of the two species:

$$
\frac{d n_{1}}{d r}=-\frac{m_{1} g}{k T} n_{1}+\frac{1}{b}\left(n_{1} F_{2}-n_{2} F_{1}\right)
$$

$$
\frac{d n_{2}}{d r}=-\frac{m_{2} g}{k T} n_{2}+\frac{1}{b}\left(n_{2} F_{1}-n_{1} F_{2}\right)
$$

where $F_{1}=n_{1} w_{1}$ and $F_{2}=n_{2} w_{2}$ are the vertical fluxes of the two gases. Addition of Eqs. (3) and (4) yields the barometric law

$$
\frac{d}{d r}\left(n_{1}+n_{2}\right)=-\left(n_{1} m_{1}+n_{2} m_{2}\right) \frac{g}{k T} .
$$

As discussed below, the density ratio $n_{1} /$ $n_{2}$ is independent of altitude when both gases are escaping, except perhaps at very large distances, so the mean molecular weight is independent of altitude. In an isothermal atmosphere the barometric law therefore becomes

$$
\frac{1}{n_{\mathrm{a}}} \frac{d n_{\mathrm{a}}}{d r}=-\frac{1}{H_{\mathrm{a}}}\left(\frac{r_{0}}{r}\right)^{2}
$$

where $n_{\mathrm{a}}=n_{1}+n_{2}$ is the ambient number density, $r$ the distance from the center of the planet, $H_{\mathrm{a}}=k T / m_{\mathrm{a}} g_{0}$ is the ambient atmospheric scale height at distance $r_{0}, m_{\mathrm{a}}=$ $\left(n_{1} m_{1}+n_{2} m_{2}\right) / n_{\mathrm{a}}$ is the mean molecular weight of the atmosphere, and $g_{0}$ is the gravitational acceleration at distance $r_{0}$. The term in the inverse square of the distance in Eq. (6) allows for the variation of gravitational acceleration with distance. The solution of the barometric law is

$$
\frac{n_{\mathrm{a}}}{n_{0}}=\exp -\left[\frac{r_{0}}{H_{\mathrm{a}}}\left(1-\frac{r_{0}}{r}\right)\right] \text {. }
$$

Define the mole fraction $X_{2}$ by

$$
X_{2}=\frac{n_{2}}{n_{1}+n_{2}}=\frac{n_{2}}{n_{\mathrm{a}}} .
$$

Differentiation of (8) yields

$$
\frac{1}{X_{2}} \frac{d X_{2}}{d r}=\frac{1}{n_{2}} \frac{d n_{2}}{d r}-\frac{1}{n_{\mathrm{a}}} \frac{d n_{\mathrm{a}}}{d r} .
$$

For the first term on the right-hand side of Eq. (9) we substitute Eq. (4); for the second term we substitute Eq. (5). The result is

$$
\begin{aligned}
\frac{1}{X_{2}} \frac{d X_{2}}{d r}=-\frac{m_{2} g}{k T}+ & \frac{1}{b}\left(F_{1}-\frac{X_{1}}{X_{2}} F_{2}\right) \\
+\left(X_{1} m_{1}+X_{2} m_{2}\right) & \frac{g}{k T}=\frac{1}{b}\left(F_{1}-\frac{X_{1}}{X_{2}} F_{2}\right) \\
& -\left(m_{2}-m_{1}\right) \frac{X_{1} g}{k T}
\end{aligned}
$$


where we have used the fact that $1-X_{2}=$ $X_{1}$.

Conservation of matter requires that the fluxes, $F_{1}$ and $F_{2}$, vary inversely as the square of the distance from the center of the planet. Gravitational acceleration also varies inversely as the square of $r$. The equation for the height variation of mole fraction therefore becomes

$$
\begin{aligned}
\frac{1}{X_{2}} \frac{d X_{2}}{d r}=\left[\frac{1}{b}\right. & \left(F_{1}^{0}-\frac{X_{1}}{X_{2}} F_{2}^{0}\right) \\
& \left.-\left(m_{2}-m_{1}\right) \frac{X_{1} g_{0}}{k T}\right]\left(\frac{r_{0}}{r}\right)^{2}
\end{aligned}
$$

where $F_{1}^{0}, F_{2}^{0}$, and $g_{0}$ are constants, the values of these quantities at reference altitude $r_{0}$. Integration of this equation is discussed by Zahnle and Kasting (1986).

A possible solution of Eq. (11) has the right-hand side equal to 0 . Then $X_{2}$ and $X_{1}$ are both constants. The expression for the flux of constituent 2 in terms of the mole fraction and the flux of constituent 1 is

$$
F_{2}^{0}=\frac{X_{2}}{X_{1}} F_{1}^{0}\left[1-\frac{b g_{0} X_{1}}{k T F_{1}^{0}}\left(m_{2}-m_{1}\right)\right] .
$$

Zahnle and Kasting (1986) obtained solutions in which the flux through a cone is maintained, although the density and velocity vary such that their product is constant. These variations generally occur at very large distances, far above the levels at which the composition of the flow has been established, and we feel that our simpler arguments remain sufficiently valid. Undoubtedly, some of these effects are due to variations of the diffusion parameter $b$ with species and temperature. Such variations are neglected here for simplicity. To derive an alternative solution suppose, now, that the right-hand side of Eq. (11) is not equal to 0 . We are interested in positive (upward) fluxes and, to be specific, suppose that $m_{2}$ is greater than $m_{1}$. Then the mole fraction of constituent $2, X_{2}$, decreases with altitude while $X_{1}$ approaches a constant value of 1 . At high altitudes, therefore, the right-hand side of Eq. (11) is dominated by the term
$-\left(X_{1} / X_{2}\right) F_{2}^{0} . X_{2}$ will be driven negative unless $F_{2}^{0}=0$. A negative mole fraction is physically impossible. Therefore, if the mole fraction $X_{2}$ varies with altitude the escape flux $F_{2}^{0}$ must be 0 . The height variation of constituent 2 in this situation is most conveniently deduced from Eq. (4) which becomes

$$
\frac{1}{n_{2}} \frac{d n_{2}}{d r}=-\left[\frac{m_{2} g_{0}}{k T}-\frac{F_{1}^{0}}{b}\right]\left(\frac{r_{0}}{r}\right)^{2} .
$$

The solution is

$$
\begin{gathered}
\frac{n_{2}}{n_{2}^{0}}=\exp -\left[\frac{r_{0}}{H^{\prime}}\left(1-\frac{r_{0}}{r}\right)\right] \\
\frac{1}{H^{\prime}}=\frac{m_{2} g_{0}}{k T}-\frac{F_{1}^{0}}{b} .
\end{gathered}
$$

In effect, this is a diffusive equilibrium profile for $n_{2}$, with the scale height augmented by the term involving the flux of constituent 1. Part of the weight of the molecules of constituent 2 is supported by a drag force corresponding to the diffusive flow of constituent 1 . Since the effective scale height, $H^{\prime}$, must be positive, this solution is valid only for a sufficiently small flux of constituent $1, F_{1}^{0}$. When the flux of constituent 1 is large, constituent 2 is carried along and the appropriate solution is Eq. (11), with the mole fractions $X_{1}$ and $X_{2}$ independent of altitude.

It is convenient to define the crossover mass $m_{\mathrm{c}}$ as follows:

$$
m_{\mathrm{c}}=m_{1}+\frac{k T F_{1}^{0}}{b g_{0} X_{1}} .
$$

Substitution in (11) yields

$$
\begin{aligned}
F_{2}^{0}=\frac{X_{2}}{X_{1}} F_{1}^{0}[1 & \left.-\frac{m_{2}-m_{1}}{m_{\mathrm{c}}-m_{1}}\right] \\
& =\frac{X_{2}}{X_{1}} F_{1}^{0}\left(\frac{m_{\mathrm{c}}-m_{2}}{m_{\mathrm{c}}-m_{1}}\right) .
\end{aligned}
$$

If we consider a range of possible values for $m_{2}$, it can be seen that the crossover mass $m_{\mathrm{c}}$ is the smallest mass for which the flux of constituent 2 is 0 . For $m_{2}=m_{\mathrm{c}}$, the composition is still independent of height; the drag 


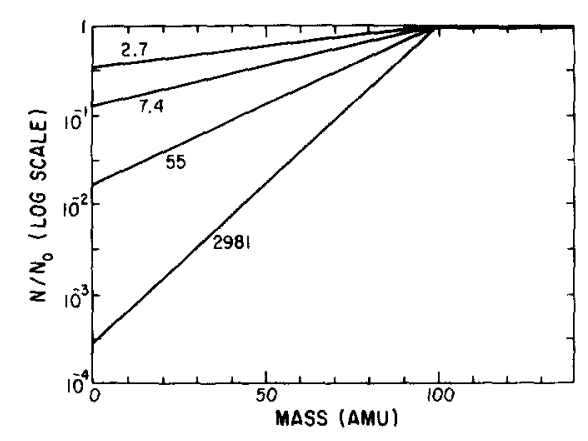

FIG. 2. The time evolution of the fractionation factor, which is the ratio of inventory remaining to initial inventory as a function of atomic mass. For purposes of illustration a constant crossover mass of $100 \mathrm{amu}$ is assumed and constant hydrogen escape flux. The parameters on the curves are related to the time-integrated hydrogen loss, $\exp \left(F_{1} t / N_{1}\right)$ for the constant inventory, or $N_{1}^{0} / N_{1}$ for the Rayleigh case.

namic escape. Figure 2 illustrates the time evolution of the mass distribution for the constant flux model, shown as a function of $m_{2}$. In this semilogarithmic plot the distribution consists of two straight lines joining at $m_{c}$ and constant for greater masses. The slopes for the low-mass branch may be seen by taking the natural logarithms of (23) and (25):

$$
\begin{aligned}
& \ln \left(\frac{N_{2}}{N_{2}^{0}}\right)=-\frac{\left(m_{\mathrm{c}}-m_{2}\right)}{\left(m_{\mathrm{c}}-m_{1}\right)}\left[\frac{F_{1}}{N_{1}^{0}}\left(t_{2}-t_{0}\right)\right] \\
& \ln \left(\frac{N_{2}}{N_{2}^{0}}\right)=-\frac{\left(m_{\mathrm{c}}-m_{2}\right)}{\left(m_{\mathrm{c}}-m_{1}\right)} \ln \left(\frac{N_{1}^{0}}{N_{1}}\right) .
\end{aligned}
$$

Both versions have the same functional dependence on $\left(m_{\mathrm{c}}-m_{2}\right) /\left(m_{\mathrm{c}}-m_{1}\right)$, and both can be represented by the same Fig. 2. Differentiation with respect to $m_{2}$ gives the slopes, which depend on the amount of the major constituent lost, expressed in terms of the atmospheric inventory $N_{1}^{0}$. It is customary to express observed fractionation in terms of the percentage or fractional change per amu, which we write as $d$; the slopes are equivalent to $\ln (1+d)$.

Mass distributions therefore appear as straight lines on semilogarithmic plots for either the model of constant hydrogen abundance in the atmosphere or the model involving Rayleigh fractionation and a decreasing hydrogen inventory, provided the crossover mass and the hydrogen escape flux are independent of time. The effect of a time-varying flux can be deduced qualitatively by considering a sequence of constant fluxes. The situation of greatest interest is probably a flux and crossover mass that decrease with time as a result of decreasing energy input into the upper atmosphere of the planet (Zahnle and Walker, 1982) and possibly also increasing mean molecular weight of the atmosphere. As the hydrodynamic escape flux decreases, the crossover mass moves to smaller values. We can qualitatively picture the mass distribution as represented by a straight line rotating around the crossover mass for a period of time. Then a smaller crossover mass becomes effective; heavier gases cease to evolve, but lighter gases continue to evolve by continued rotation of the straight line that represents the mass distribution. An escape flux that decreases with time will therefore result in a mass distribution that plots as a curved line, concave downward in semilogarithmic coordinates rather than the straight lines shown in Fig. 2. This behavior is illustrated quantitatively for a few cases in Section 5.

\section{REQUIRED FLUXES}

A large hydrogen flux can occur if there is an adequate source (which may simply be a massive atmosphere) and sufficient energy. Energy-limited escape has been studied by Watson et al. (1981); the Venus models of Kasting and Pollack (1983) were partially source limited as well. The work of Kasting and Zahnle (1986) was carried out in parallel with the present study. The limitation is found to arise at very high altitudes, where the only significant heat source is solar ionizing radiation. To a reasonable approximation, the required energy per atomic mass unit is just the escape energy of a hydrogen atom $G M m / r$, where $G$ is the gravitational constant, $M$ and $m$ are the masses of the planet and a hydrogen 
atom, and $r$ is the radius of the relevant level, often considerably greater than the planetary radius $a$. Thus, if the global-mean solar energy input is $\phi$, the energy-limited escape flux is $F_{1}=\phi r / G M m$ (amu/sec). Replacing the gravitational acceleration $g$ by $G M / r^{2}$, we can write (16) as

$$
\begin{aligned}
m_{\mathrm{c}}-m_{1}=\frac{k T}{b X_{1}} & \frac{\phi r^{3}}{G^{2} M^{2} m} \\
& =\left(\frac{3}{4 \pi G \rho}\right)^{2} \frac{\phi k T}{b X_{1} m} \frac{r^{3}}{a^{6}}
\end{aligned}
$$

If $r$ is around $2 a$, the last term is $8 / a^{3}$. A small mean density $\rho$, typical of small bodies, is almost as important as a small radius. The estimates of Table I use $r=a, b$ $=2.2 \times 10^{19} \mathrm{~cm}^{-1} \mathrm{sec}^{-1}$, and take $T=$ $400^{\circ} \mathrm{K}$, as obtained for Venus by Kasting and Pollack (1983). The solar input is roughly appropriate to the present Earth. A body like the Moon, perhaps somewhat farther from the Sun, is therefore in the right size range for important blowoff fractionation, with a crossover mass approaching 200. On almost any object, the actual flux may be source limited at a value less than obtained here. For larger or more distant bodies it is necessary to consider the history of the solar UV output.

This history has been discussed byZahnle and Walker (1982) and Canuto et al. (1982). For the region below $1000 \mathrm{~A}$, Zahnle and Walker give a curve from $10^{6}$ to $4 \times 10^{9}$

\section{TABLE I}

ENERGY-Limited FluXes (amu $\mathrm{cm}^{-2} \mathrm{sec}^{-1}$ ) AND Corresponding Crossover Masses for a Global-MEAN SOLAR INPUT of $1 \mathrm{erg} \mathrm{cm} \mathrm{cm}^{-2} \mathrm{sec}^{-1}$

\begin{tabular}{lcccc}
\hline & Earth & Mars & Moon & Planetesimal \\
\hline Flux & $1 \times 10^{12}$ & $5 \times 10^{12}$ & $2 \times 10^{13}$ & $5 \times 10^{13}$ \\
$m_{\mathrm{c}}$ & 2.5 & 20 & 197 & 1030 \\
$\lambda$ & 300 & 61 & 14 & 4.5 \\
\hline
\end{tabular}

Note. The planetesimal has the density of the Moon and a radius of $1000 \mathrm{~km}$. The last line shows thermal escape parameters for a mass of $\mathbf{4 0}$ and a temperature of $1000^{\circ} \mathrm{K}$. years that can be represented by

$$
\phi=10^{8} t^{-5 / 6}
$$

in units of the present value, with $t$ in years. The factors are 1000,150 , and 22 at $10^{6}, 10^{7}$, and $10^{8}$ years, respectively. The latter two are perhaps most relevant to atmospheric history; they would put the energy-limited crossover mass for the Earth at 225 and 34 at these times.

Donahue (1986) has considered a scenario of Jeans escape of the noble gases from growing planetesimals in the absence of hydrogen. Table I includes values of the escape parameter $\lambda=G M m / k T r$ for $m=40$ amu and a temperature of $1000^{\circ} \mathrm{K}$. Since copious escape requires $\lambda$ of order 10 or smaller, and even heavier gases must be considered, it can be seen that the Jeans process requires somewhat smaller bodies than the blowoff-assisted one.

\section{FRACTIONATION OF NOBLE GASES}

We present here some simple examples of how this theory might be applied to problems in the evolution of planetary atmospheres. The first of these considers the fractionation of meteoritic xenon isotopes to generate terrestrial xenon isotopic abundances, and the second the fractionated mass distribution, derived from SNC meteorite data, that appears to relate the relative elemental abundances of noble gases in the atmospheres of Mars and Earth. Relevant data are shown in Tables II-IV.

Earth. It was recognized early in the study of meteoritic xenon that the average carbonaceous chondrite (AVCC) and terrestrial atmospheric xenon compositions are related by mass fractionation at the four light isotopes ${ }^{124} \mathrm{Xe},{ }^{126} \mathrm{Xe},{ }^{128} \mathrm{Xe}$, and ${ }^{130} \mathrm{Xe}$ (Krummenacher et al., 1962). However, heavy isotope abundances deviate sharply from the fractionation pattern defined by the light isotopes. As discussed below, this is now thought to be due to heavy isotope components in both carbonaceous chondrite xenon and contemporary terrestrial xenon that were not present when the frac- 
TABLE II

Isotopic Compositions of Meteoritic and TerRestrial Xenon

(From Pepin and Phinney (1978) and References Therein)

\begin{tabular}{|c|c|c|c|c|c|c|c|c|c|}
\hline & ${ }^{124} \mathrm{Xe}$ & ${ }^{126} \mathrm{Xe}$ & ${ }^{128} \mathrm{Xe}$ & ${ }^{129} \mathrm{Xe}$ & ${ }^{130} \mathrm{Xe}$ & ${ }^{131} \mathrm{Xe}$ & ${ }^{132} \mathrm{Xe}$ & ${ }^{134} \mathrm{Xe}$ & ${ }^{136} \mathrm{Xe}$ \\
\hline AVCC-Xenon & $\begin{array}{l}2.851 \\
\quad \pm .051\end{array}$ & $\begin{array}{l}2.512 \\
1 \quad \pm 0.40\end{array}$ & $\begin{array}{l}50.73 \\
\quad \pm .38\end{array}$ & $\begin{array}{l}628.7 \\
\pm 2.9\end{array}$ & $\equiv 100$ & $\begin{array}{l}504.3 \\
\quad \pm 2.8\end{array}$ & $\begin{array}{l}615.0 \\
\pm 2.7\end{array}$ & $\begin{array}{l}235.9 \\
\pm 1.3\end{array}$ & $\begin{array}{l}198.8 \\
\pm 1.2\end{array}$ \\
\hline U-Xenon & 2.947 & 2.541 & 50.873 & 628.7 & $\equiv 100$ & 499.58 & 604.79 & 212.88 & 166.34 \\
\hline $\begin{array}{l}\text { Contemporary } \\
\text { terrestrial Xe }\end{array}$ & $\begin{array}{l}2.337 \\
\quad \pm .007\end{array}$ & $\begin{array}{l}2.180 \\
7 \quad \pm .011\end{array}$ & $\begin{array}{l}47.146 \\
\pm .047\end{array}$ & $\begin{array}{l}649.58 \\
\pm 0.58\end{array}$ & $=100$ & $\begin{array}{l}521.27 \\
\quad \pm 0.59\end{array}$ & $\begin{array}{l}660.68 \\
\pm 0.53\end{array}$ & $\begin{array}{l}256.28 \\
\quad \pm 0.37\end{array}$ & $\begin{array}{l}217.63 \\
\quad \pm 0.22\end{array}$ \\
\hline $\begin{array}{l}\text { Nonradiogenic } \\
\text { terrestrial Xe }\end{array}$ & $\begin{array}{l}2.337 \\
\quad \pm .007\end{array}$ & $\begin{array}{l}2.180 \\
7 \quad \pm .011\end{array}$ & $\begin{array}{l}47.146 \\
\pm .047\end{array}$ & $\begin{array}{l}605.3 \\
\pm 2.9\end{array}$ & $=100$ & $\begin{array}{l}518.73 \\
\quad \pm 0.71\end{array}$ & $\begin{array}{l}651.8 \\
\pm 1.3\end{array}$ & $\begin{array}{l}247.0 \\
\pm 1.3\end{array}$ & $\begin{array}{l}207.5 \\
\quad \pm 1.3\end{array}$ \\
\hline
\end{tabular}

tionation occurred. It is interesting to note, however, that a two-stage fractionation of AVCC-Xe in hydrodynamic escape can generate the present-day terrestrial $\mathrm{Xe}$ composition for both light and heavy isotopes. Data from Table II are plotted in Fig. 3 as abundances of $\mathrm{Xe}$ isotopes, normalized to ${ }^{130} \mathrm{Xe}$, in the Earth's atmosphere relative to average carbonaceous chondrites. For purposes of this discussion we assume that AVCC-Xe represented the initial concentrations of these isotopes on Earth, and that molecular hydrogen was the predominant escaping species so that $m_{1}=2$. The figure indicates that the mass distribution can be reasonably represented, assuming a con- stant hydrogen escape flux and either the constant inventory (Eq. (23)) or Rayleigh (Eq. (25)) models, by an escape episode with a crossover mass of $140 \mathrm{amu}$ that yielded a slope parameter $d=0.007$, plus an escape episode with a crossover mass of $131.7 \mathrm{amu}$ that yielded a slope parameter $d$ $=0.028$.

In more recent work on isotopic systematics in Solar System xenon, evidence has mounted that both AVCC and terrestrial xenon are mixtures of several components of different origin. Pepin and Phinney (1978) have proposed that there is a quantitative single-stage mass fractionation relationship between a primordial " $\mathrm{U}-\mathrm{Xe}$ "

TABLE III

absolute Number Densities of Carbon Dioxide, Nitrogen, and Noble Gases Measured in the Ground-Level Martian Atmosphere by Viking, and in Lithology C (Glass) OF THE EETA 79001 SHERGOTTITE

\begin{tabular}{|c|c|c|c|c|c|c|c|c|}
\hline & $\begin{array}{c}\mathrm{CO}_{2} \\
\left(\times 10^{17}\right)\end{array}$ & $\begin{array}{c}N_{2} \\
\left(\times 10^{15}\right)\end{array}$ & $\begin{array}{c}{ }^{20} \mathrm{Ne} \\
\left(\times 10^{11}\right)\end{array}$ & $\begin{array}{c}{ }^{36} \mathrm{Ar} \\
\left(\times 10^{12}\right)\end{array}$ & $\begin{array}{c}{ }^{40} \mathrm{Ar} \\
\left(\times 10^{15}\right)\end{array}$ & $\begin{array}{c}{ }^{84} \mathrm{Kr} \\
\left(\times 10^{10}\right)\end{array}$ & $\begin{array}{c}{ }^{130} \mathrm{Xe} \\
\left(\times 10^{08}\right)\end{array}$ & $\begin{array}{c}{ }^{132} \mathrm{Xe} \\
\left(\times 10^{09}\right)\end{array}$ \\
\hline $\begin{array}{l}\text { Mars } \\
\text { atmosphere }\end{array}$ & $\begin{array}{l}2.24 \\
\quad \pm 0.22\end{array}$ & $\begin{array}{l}6.3 \\
\quad \pm 1.3\end{array}$ & $\begin{array}{l}5.4 \\
(2.2-12.9)\end{array}$ & $\begin{array}{l}1.27 \\
\pm 0.41\end{array}$ & $\begin{array}{l}3.82 \\
\quad \pm 0.75\end{array}$ & $\begin{array}{l}4.0 \\
(1.3-12.6)\end{array}$ & - & $\begin{array}{c}3.6 \\
(1.1-10.0)\end{array}$ \\
\hline $\begin{array}{l}\text { EETA } 79001 \\
\text { glass }^{b}\end{array}$ & $\begin{array}{l}4.0^{c} \\
\quad \pm 1.8\end{array}$ & $\begin{array}{l}6.0^{d} \\
\quad \pm 2.0\end{array}$ & $\begin{array}{l}5.3^{e} \\
\quad \pm 0.4\end{array}$ & $\begin{array}{l}1.44^{d} \\
\pm 0.30\end{array}$ & $\begin{array}{l}3.25^{d} \\
\quad \pm 0.74\end{array}$ & $\begin{array}{l}5.08^{f . g} \\
\quad \pm 0.29\end{array}$ & $\begin{array}{l}3.87^{f} \\
\quad \pm 0.50\end{array}$ & $\begin{array}{l}2.50^{f, g} \\
\pm 0.32\end{array}$ \\
\hline
\end{tabular}

Note. Units are molecules or atoms per cubic centimeter.

a Atmospheric mixing ratios from Owen et al. (1977) and Pollack and Black (1982); ground-level atmospheric density $\rho_{0}=1.7 \times 10^{-5} \mathrm{~g} / \mathrm{cm}^{3}$, mean molecular weight $\bar{M}=43.5 \mathrm{u}$.

${ }^{b}$ Assumed glass density $=3.3 \mathrm{~g} / \mathrm{cm}^{3}$.

$c$ Wright et al. (1986).

${ }^{d}$ Calculated from measured two-component $\mathrm{N}$-Ar mixing systematics (Wiens et al., 1986), assuming $\delta^{15} \mathrm{~N}=$ +620 permil (Nier and McElroy, 1977) in the trapped component.

e Average of data from Wiens et al. (1986) and Swindle et al. (1986).

$f$ Average of data from Becker and Pepin (1984) and Swindle et al. (1986).

$g$ Bogard et al. (1984) reported somewhat higher values: ${ }^{84} \mathrm{Kr}=6.4 \pm 1.0 \times 10^{10},{ }^{132} \mathrm{Xe}=3.3 \pm 0.6 \times 10^{09}$. 
TABLE IV

InVEntories of NonRadiogenic and Radiogenic Noble Gases IN THE ATMOSPHERES OF MARS AND EARTH

\begin{tabular}{|c|c|c|c|c|c|c|}
\hline & \multicolumn{4}{|c|}{ Nonradiogenic } & \multicolumn{2}{|c|}{ Radiogenic } \\
\hline & $\begin{array}{c}{ }^{20} \mathrm{Ne} \\
\left(\times 10^{-15}\right)\end{array}$ & $\begin{array}{c}{ }^{36} \mathrm{Ar} \\
\left(\times 10^{-15}\right)\end{array}$ & $\begin{array}{c}{ }^{84} \mathrm{Kr} \\
\left(\times 10^{-16}\right)\end{array}$ & $\begin{array}{c}{ }^{130} \mathrm{Xe} \\
\left(\times 10^{-18}\right)\end{array}$ & $\begin{array}{c}{ }^{40} \mathrm{Ar} \\
\left(\times 10^{-11}\right)\end{array}$ & $\begin{array}{c}{ }^{129} \mathrm{Xe} \\
\left(\times 10^{-17}\right)\end{array}$ \\
\hline Mars $^{a}$ & $\begin{array}{l}2.19 \\
\quad \pm 0.17\end{array}$ & $\begin{array}{l}6.0 \\
\quad \pm 1.2\end{array}$ & $\begin{array}{l}2.10 \\
\quad \pm 0.12\end{array}$ & $\begin{array}{l}1.60 \\
\quad \pm 0.21\end{array}$ & $\begin{array}{l}1.35 \\
\quad \pm 0.31\end{array}$ & $\begin{array}{l}2.48^{b, c} \\
\quad \pm 0.33\end{array}$ \\
\hline Earth & $\begin{array}{l}502 \\
\quad \pm 2\end{array}$ & $\begin{array}{l}958 \\
\pm 3\end{array}$ & $\begin{array}{l}198 \\
\pm 2\end{array}$ & $\begin{array}{l}108 \\
\pm 2\end{array}$ & $\begin{array}{l}28.35 \\
\quad \pm 0.03\end{array}$ & $\begin{array}{l}70.2^{c} \\
\pm 0.9\end{array}$ \\
\hline
\end{tabular}

Note. Units are moles per gram planet.

${ }^{a}$ Calculated from the EETA 79001 noble gas mixing ratios (Table III), and a Mars atmosphere with ground-level density $\rho_{0}=1.7 \times 10^{-5} \mathrm{~g} / \mathrm{cm}^{3}$, mean molecular weight $\bar{M}=43.5 \mathrm{u}$, and mass $=2.7 \times 10^{19} \mathrm{~g}$.

${ }^{b}{ }^{129} \mathrm{Xe}^{/ 130} \mathrm{Xe}=15.52 \pm 0.16$ (Swindle et al., 1986).

c Mixture of radiogenic and nonradiogenic components. For Earth atmosphere, ${ }^{129} \mathrm{Xe}_{\mathrm{r}} / 129 \mathrm{Xe}$ $\simeq 0.068 \pm 0.005$ (Pepin and Phinney, 1978); for Mars atmosphere, assuming that $\left({ }^{129} \mathrm{Xe} /{ }^{130} \mathrm{Xe}\right)_{\mathrm{nr}}$ $\simeq 6.11 \pm 0.18$ (Swindle et al., 1986 ), ${ }^{129} \mathrm{Xe}_{\mathrm{r}} /{ }^{129} \mathrm{Xe}=0.61 \pm 0.02$. Then the radiogenic ${ }^{129} \mathrm{Xe}$ inventories are $\left({ }^{(29} \mathrm{Xe}_{\mathrm{r}}\right)_{\delta}=1.51 \pm 0.20 \times 10^{-17}$ and $\left({ }^{129} \mathrm{Xe}_{\mathrm{r}}\right)_{\oplus}=4.77 \pm 0.36 \times 10^{-17}$.

component inferred to exist in the early solar nebula, and nonradiogenic xenon in the Earth's atmosphere. U-Xe is closely related to AVCC-Xe, but does not contain a

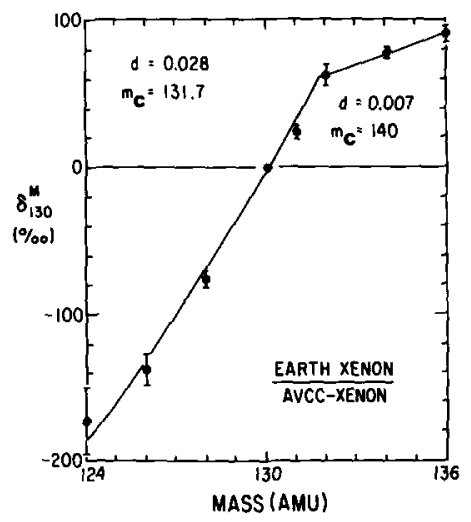

FIG. 3. Fractionation of terrestrial xenon isotopes as a function of atomic mass, relative to average carbonaceous chondrite (AVCC) xenon. The data are interpreted in terms of a two-stage escape model with constant hydrogen flux, the first episode with a crossover mass of $140 \mathrm{amu}$ followed by a longer episode with a crossover mass of $131.7 \mathrm{amu}$. The ordinate is the difference of the ratios of isotope $M$ to isotope 130 for Earth and AVCC, normalized to the latter and expressed in parts per thousand. nucleogenetic heavy isotope component that is abundant in AVCC-Xe. Nonradiogenic terrestrial $\mathrm{Xe}$ reflects the isotope abundances that would have pertained to the ancient Earth, immediately following the fractionation but prior to the addition of ${ }^{129} \mathrm{Xe}$ and ${ }^{131-136} \mathrm{Xe}$ from in situ decay of ${ }^{129} \mathrm{I}$, ${ }^{238} \mathrm{U}$, and ${ }^{244} \mathrm{Pu}$ in the Earth over geologic time. In the present context, the question is whether Pepin and Phinney's fractionation relation between $\mathrm{U}-\mathrm{Xe}$ and nonradiogenic terrestrial Xe could have been produced in an episode of hydrodynamic escape of hydrogen from the protoearth.

The U-Xe and nonradiogenic terrestrial Xe compositions from Table II, again normalized to ${ }^{130} \mathrm{Xe}$, are plotted relative to each other in Fig. 4. Here we assume that Xe on Earth was initially U-Xe and, as before, that hydrogen was the principal escaping species. For constant escape flux, and any crossover mass $m_{\mathrm{c}} \geq 136 \mathrm{amu}$, Eq. (23) or Eq. (25) then yields a slope parameter $d$ $=0.381$ for best fit, shown by the dashed curve, to the Fig. 4 mass distribution.

This fractionation pattern cannot quite match the curvature of the observed mass distribution. However, we noted above that 


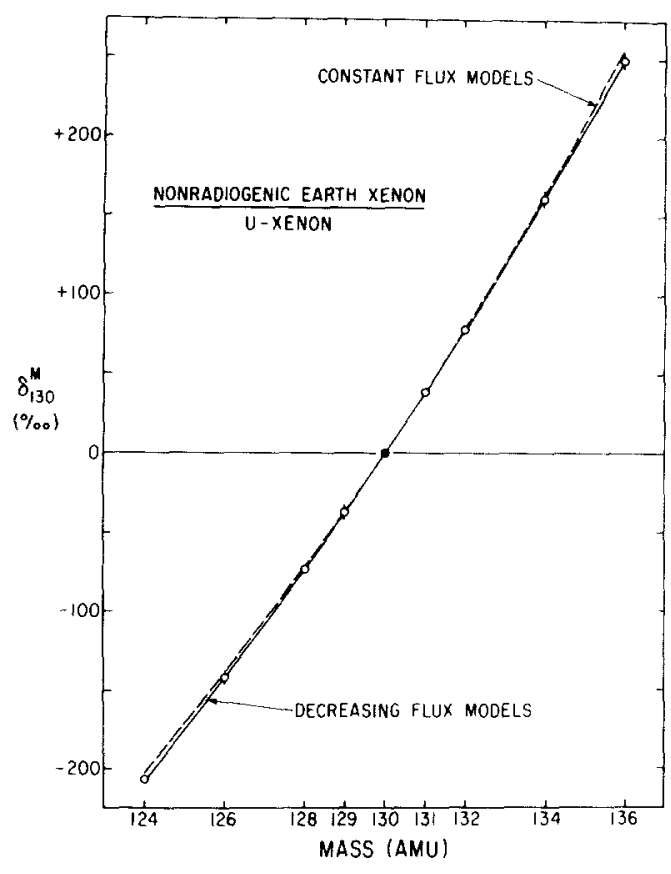

FIG. 4. Fractionation of terrestrial xenon isotopes as a function of atomic mass relative to $U-X e$. The dashed curve is generated by single-stage constant flux models, the solid curve by declining flux models. Isotope data are listed in Table II and model parameters in Table $\mathrm{V}$.

an escape flux decreasing with time results in downward curvature of the fractionation function, and this model can yield exact fits to the data. The solid curve in Fig. 4 represents the solutions of Eq. (21) for a hydrogen flux that declines with time either exponentially $\left(f(t)=\exp \left(-k\left[t-t_{0}\right]\right)\right)$ or according to a power law $\left(f(t)=\left(t_{0} / t\right)^{s}\right.$, with $s \geq 1$ ).

Parameter values from the solutions of Eqs. (21), (23), and (25) for all the xenon isotope fractionation scenarios discussed in this section are listed in Table V. Declining flux models lead to higher xenon depletions, initial hydrogen escape rates, and integrated hydrogen losses in the escape episodes than the constant flux models. This is particularly true for certain cases of power law flux decrease. We have chosen $s=1.5$ to illustrate this model in Table $\mathrm{V}$, but for appropriate values of $m_{\mathrm{c}}^{0}$ there are fits within error for $s \geq 0$.

for $s \geq 1$. With $s=1$,

5500 and $F_{1}^{0}$ is $3.3 \times 10^{2} a_{c t}$ most 10 times the initial $y_{\mathrm{e}} m_{\mathrm{c}} \mathrm{ch}_{\mathrm{e}_{\mathrm{S}}}$ quired for $s=1.5$. In any ev, $m^{\prime \prime}$ availability of sufficient hydroe al ergy input), it is clear from Fig. ? non fractionation in hydrodynami can account very well for the fractic relation between $\mathrm{U}-\mathrm{Xe}$ and nonradio ${ }_{\varepsilon}$ terrestrial Xe derived by Pepin and Pim.. ney. Moreover, it provides for the first time a feasible planetary environment in which the fractionating process could have operated.

We now examine in more detail the flux. energy, and inventory requirements for xenon fraction in hydrodynamic escape, using the AVCC-terrestrial Xe fractionation as an example. A crossover mass of $140 \mathrm{amu}$ requires a hydrogen escape flux from Earth of $8.1 \times 10^{13} \mathrm{~mol} / \mathrm{cm}^{2} / \mathrm{sec}$ (Table V). The energy required to lift a molecule out of the Earth's gravitational field is $m_{1} g_{0} r_{0}=2.1 \times$ $10^{-12} \mathrm{erg}$, where $r_{0}$ is the radius of the planet $=6.37 \times 10^{8} \mathrm{~cm}$. The flux of energy carried away from the planet by escaping hydrogen molecules is therefore $168.6 \mathrm{erg} / \mathrm{cm}^{2} / \mathrm{sec}$; the rate of supply of energy to the upper atmosphere, presumably by absorption of solar extreme ultraviolet radiation, must be at least this large. This energy flux is much larger than the present-day rate of thermospheric heating $\left(\sim 1 \mathrm{erg} / \mathrm{cm}^{2} / \mathrm{sec}\right)$, but the ultraviolet energy flux from the young Sun was probably much larger still (Zahnle and Walker, 1982).

The xenon mass fractionations shown in Fig. 3 are extrapolated to smaller masses in Fig. 5. The figure shows that the implied loss of helium is a reduction in inventory by a factor of 100. Loss of the heavier noble gases is smaller. Comparable fractionations could have applied to other terrestrial volatiles like carbon, nitrogen, and sulfur, but the fractionations implied by Fig. 5 would have been effective only if these constituents were in the atmosphere during the escape episode. If these reactive constituents 
TABLE IV

InVentories of NonRadiogenic and Radiogenic Noble Gases IN THE ATMOSPHERES OF MARS AND EARTH

\begin{tabular}{|c|c|c|c|c|c|c|}
\hline & \multicolumn{4}{|c|}{ Nonradiogenic } & \multicolumn{2}{|c|}{ Radiogenic } \\
\hline & $\begin{array}{c}{ }^{20} \mathrm{Ne} \\
\left(\times 10^{-15}\right)\end{array}$ & $\begin{array}{c}{ }^{36} \mathrm{Ar} \\
\left(\times 10^{-15}\right)\end{array}$ & $\begin{array}{c}{ }^{84} \mathrm{Kr} \\
\left(\times 10^{-16}\right)\end{array}$ & $\begin{array}{c}{ }^{130} \mathrm{Xe} \\
\left(\times 10^{-18}\right)\end{array}$ & $\begin{array}{c}{ }^{40} \mathrm{Ar} \\
\left(\times 10^{-11}\right)\end{array}$ & $\begin{array}{c}{ }^{129} \mathrm{Xe} \\
\left(\times 10^{-17}\right)\end{array}$ \\
\hline Mars $^{a}$ & $\begin{array}{l}2.19 \\
\quad \pm 0.17\end{array}$ & $\begin{array}{l}6.0 \\
\quad \pm 1.2\end{array}$ & $\begin{array}{l}2.10 \\
\quad \pm 0.12\end{array}$ & $\begin{array}{l}1.60 \\
\pm 0.21\end{array}$ & $\begin{array}{l}1.35 \\
\pm 0.31\end{array}$ & $\begin{array}{l}2.48^{b, c} \\
\quad \pm 0.33\end{array}$ \\
\hline Earth & $\begin{array}{l}502 \\
\quad \pm 2\end{array}$ & $\begin{array}{l}958 \\
\pm 3\end{array}$ & $\begin{array}{l}198 \\
\pm 2\end{array}$ & $\begin{array}{l}108 \\
\pm 2\end{array}$ & $\begin{array}{l}28.35 \\
\quad \pm 0.03\end{array}$ & $\begin{array}{l}70.2^{c} \\
\pm 0.9\end{array}$ \\
\hline
\end{tabular}

Note. Units are moles per gram planet.

a Calculated from the EETA 79001 noble gas mixing ratios (Table III), and a Mars atmosphere with ground-level density $\rho_{0}=1.7 \times 10^{-5} \mathrm{~g} / \mathrm{cm}^{3}$, mean molecular weight $\bar{M}=43.5 \mathrm{u}$, and mass $=2.7 \times 10^{19} \mathrm{~g}$.

${ }^{b}{ }^{129} \mathrm{Xe} /{ }^{130} \mathrm{Xe}=15.52 \pm 0.16$ (Swindle et al., 1986).

c Mixture of radiogenic and nonradiogenic components. For Earth atmosphere, ${ }^{129} \mathrm{Xe}_{\mathrm{r}}{ }^{129} \mathrm{Xe}$ $=0.068 \pm 0.005$ (Pepin and Phinney, 1978); for Mars atmosphere, assuming that $\left({ }^{129} \mathrm{Xe} /{ }^{130} \mathrm{Xe}\right)_{\mathrm{nr}}$ $\simeq 6.11 \pm 0.18$ (Swindle et al., 1986), ${ }^{129} \mathrm{Xe}_{\mathrm{r}} /{ }^{129} \mathrm{Xe} \simeq 0.61 \pm 0.02$. Then the radiogenic ${ }^{129} \mathrm{Xe}$ inventories are $\left({ }^{129} \mathrm{Xe}_{\mathrm{r}}\right)_{\dot{\delta}}=1.51 \pm 0.20 \times 10^{-17}$ and $\left({ }^{129} \mathrm{Xe}_{r}\right)_{\oplus}=4.77 \pm 0.36 \times 10^{-17}$.

component inferred to exist in the early solar nebula, and nonradiogenic xenon in the Earth's atmosphere. U-Xe is closely related to AVCC-Xe, but does not contain a

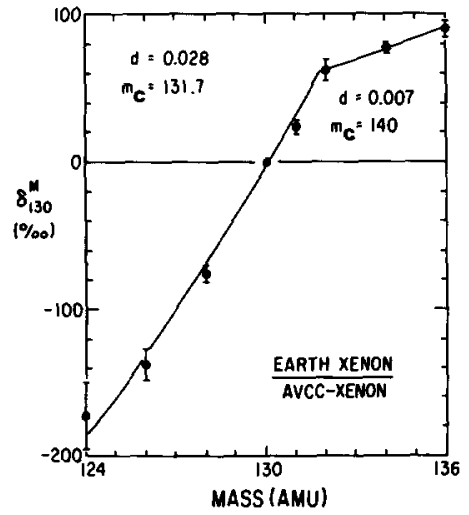

FIG. 3. Fractionation of terrestrial xenon isotopes as a function of atomic mass, relative to average carbonaceous chondrite (AVCC) xenon. The data are interpreted in terms of a two-stage escape model with constant hydrogen flux, the first episode with a crossover mass of $140 \mathrm{amu}$ followed by a longer episode with a crossover mass of $131.7 \mathrm{amu}$. The ordinate is the difference of the ratios of isotope $M$ to isotope 130 for Earth and AVCC, normalized to the latter and expressed in parts per thousand. nucleogenetic heavy isotope component that is abundant in AVCC-Xe. Nonradiogenic terrestrial $\mathrm{Xe}$ reflects the isotope abundances that would have pertained to the ancient Earth, immediately following the fractionation but prior to the addition of ${ }^{129} \mathrm{Xe}$ and ${ }^{131-136} \mathrm{Xe}$ from in situ decay of ${ }^{129} \mathrm{I}$, ${ }^{238} \mathrm{U}$, and ${ }^{244} \mathrm{Pu}$ in the Earth over geologic time. In the present context, the question is whether Pepin and Phinney's fractionation relation between $\mathrm{U}-\mathrm{Xe}$ and nonradiogenic terrestrial Xe could have been produced in an episode of hydrodynamic escape of hydrogen from the protoearth.

The U-Xe and nonradiogenic terrestrial Xe compositions from Table II, again normalized to ${ }^{130} \mathrm{Xe}$, are plotted relative to each other in Fig. 4. Here we assume that $\mathrm{Xe}$ on Earth was initially $\mathrm{U}-\mathrm{Xe}$ and, as before, that hydrogen was the principal escaping species. For constant escape flux, and any crossover mass $m_{\mathrm{c}} \geq 136 \mathrm{amu}$, Eq. (23) or Eq. (25) then yields a slope parameter $d$ $=0.381$ for best fit, shown by the dashed curve, to the Fig. 4 mass distribution.

This fractionation pattern cannot quite match the curvature of the observed mass distribution. However, we noted above that 


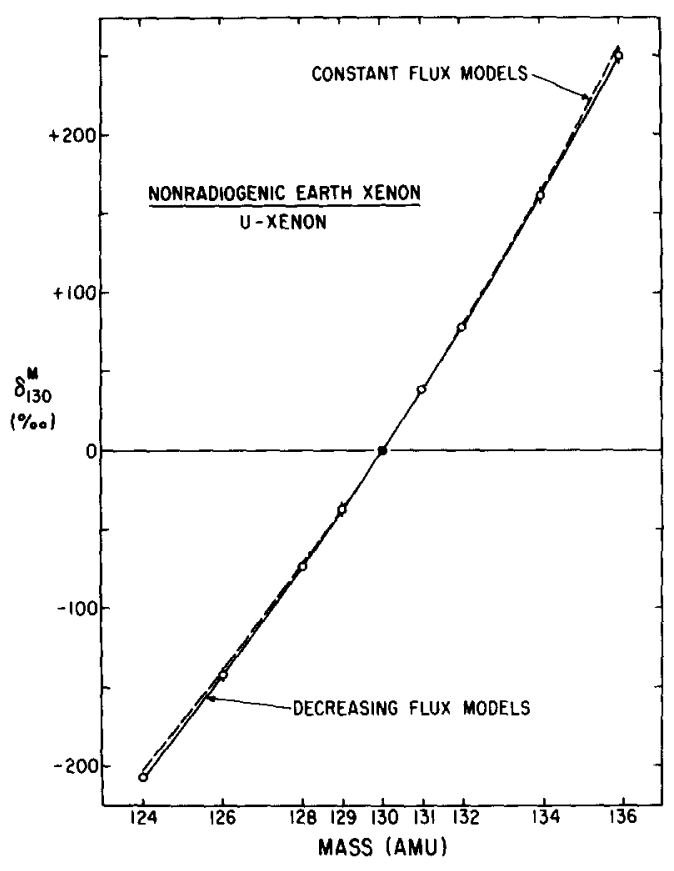

Fig. 4. Fractionation of terrestrial xenon isotopes as a function of atomic mass relative to $\mathrm{U}-\mathrm{Xe}$. The dashed curve is generated by single-stage constant flux models, the solid curve by declining flux models. Isotope data are listed in Table II and model parameters in Table $\mathrm{V}$.

an escape flux decreasing with time results in downward curvature of the fractionation function, and this model can yield exact fits to the data. The solid curve in Fig. 4 represents the solutions of Eq. (21) for a hydrogen flux that declines with time either exponentially $\left(f(t)=\exp \left(-k\left[t-t_{0}\right]\right)\right)$ or according to a power law $\left(f(t)=\left(t_{0} / t\right)^{s}\right.$, with $s \geq 1)$.

Parameter values from the solutions of Eqs. (21), (23), and (25) for all the xenon isotope fractionation scenarios discussed in this section are listed in Table V. Declining flux models lead to higher xenon depletions, initial hydrogen escape rates, and integrated hydrogen losses in the escape episodes than the constant flux models. This is particularly true for certain cases of power law flux decrease. We have chosen $s=1.5$ to illustrate this model in Table $\mathrm{V}$, but for appropriate values of $m_{\mathrm{c}}^{0}$ there are fits within error for $s \geq 0.5$, and exact matches for $s \geq 1$. With $s=1$, for example, $m_{\mathrm{c}}^{0} \sim$ 5500 and $F_{1}^{0}$ is $3.3 \times 10^{15} \mathrm{~mol} / \mathrm{cm}^{2} / \mathrm{sec}$, almost 10 times the initial escape rate required for $s=1.5$. In any event, given the availability of sufficient hydrogen (and energy input), it is clear from Fig. 4 that xenon fractionation in hydrodynamic escape can account very well for the fractionation relation between $\mathrm{U}-\mathrm{Xe}$ and nonradiogenic terrestrial Xe derived by Pepin and Phinney. Moreover, it provides for the first time a feasible planetary environment in which the fractionating process could have operated.

We now examine in more detail the flux, energy, and inventory requirements for xenon fraction in hydrodynamic escape, using the AVCC-terrestrial Xe fractionation as an example. A crossover mass of $140 \mathrm{amu}$ requires a hydrogen escape flux from Earth of $8.1 \times 10^{13} \mathrm{~mol} / \mathrm{cm}^{2} / \mathrm{sec}$ (Table V). The energy required to lift a molecule out of the Earth's gravitational field is $m_{1} g_{0} r_{0}=2.1 \times$ $10^{-12} \mathrm{erg}$, where $r_{0}$ is the radius of the planet $=6.37 \times 10^{8} \mathrm{~cm}$. The flux of energy carried away from the planet by escaping hydrogen molecules is therefore $168.6 \mathrm{erg} / \mathrm{cm}^{2} / \mathrm{sec}$; the rate of supply of energy to the upper atmosphere, presumably by absorption of solar extreme ultraviolet radiation, must be at least this large. This energy flux is much larger than the present-day rate of thermospheric heating $\left(\sim 1 \mathrm{erg} / \mathrm{cm}^{2} / \mathrm{sec}\right)$, but the ultraviolet energy flux from the young Sun was probably much larger still (Zahnle and Walker, 1982).

The xenon mass fractionations shown in Fig. 3 are extrapolated to smaller masses in Fig. 5. The figure shows that the implied loss of helium is a reduction in inventory by a factor of 100 . Loss of the heavier noble gases is smaller. Comparable fractionations could have applied to other terrestrial volatiles like carbon, nitrogen, and sulfur, bu the fractionations implied by Fig. 5 woulc have been effective only if these constitu. ents were in the atmosphere during the es. cape episode. If these reactive constituent: 


\section{TABLE V}

Parameter Values for Mass Fractionation of Xenon Isotopes in Hydrodynamic Escape, from the Rayleigh Fractionation Model with Constant Hydrogen Escape Flux, and from the Constant Hydrogen InVentory MOdel with CONSTANT OR TIME-Dependent EsCape FluX $F_{1}=$ $F_{1}^{0} f(t)$

\begin{tabular}{|c|c|c|c|c|c|c|c|}
\hline Model & $F(t)$ & $m_{\mathrm{c}}^{0}$ & $\alpha^{a}$ & ${ }^{130} \mathrm{Xe} /\left({ }^{130} \mathrm{Xe}\right)^{0}$ & $N_{1} / N_{1}^{0}$ & $\Delta N_{1} / N_{1}^{b}$ & $F_{1}^{c}$ \\
\hline \multicolumn{8}{|c|}{ Fractionation of AVCC-Xenon } \\
\hline $\begin{array}{l}\text { Rayleigh, } \\
\text { constant flux (Eq. (25)) }\end{array}$ & 1 & 140 & 4.75 & 0.71 & $8.7 \times 10^{-3}$ & - & $8.1 \times 10^{13}$ \\
\hline $\begin{array}{l}\text { Constant inventory, } \\
\text { constant flux (Eq. (23)) }\end{array}$ & 1 & 140 & 4.75 & 0.71 & - & 4.75 & $8.1 \times 10^{13}$ \\
\hline \multicolumn{8}{|c|}{ Fractionation of U-Xenon } \\
\hline $\begin{array}{l}\text { Rayleigh, } \\
\text { constant flux (Eq. (25)) }\end{array}$ & 1 & $\geq 136$ & $\geq 5.10$ & $\leq 0.80$ & $\leq 6.1 \times 10^{-3}$ & - & $\geq 7.9 \times 10^{13}$ \\
\hline $\begin{array}{l}\text { Constant inventory, } \\
\text { constant flux (Eq. (23)) }\end{array}$ & 1 & $\geq 136$ & $\geq 5.10$ & $\leq 0.80$ & - & $\geq 5.10$ & $\geq 7.9 \times 10^{13}$ \\
\hline $\begin{array}{l}\text { Constant inventory, } \\
\text { declining flux (Eq. (21)) }\end{array}$ & $e^{-k\left(t-t_{0}\right)}$ & 345 & 13.13 & $3.3 \times 10^{-2}$ & - & $8.46^{d}$ & $2.0 \times 10^{14 e}$ \\
\hline $\begin{array}{l}\text { Constant inventory, } \\
\text { declining flux (Eq. (21)) }\end{array}$ & $\left(t_{0} / t\right)^{1.5}$ & 625 & 12.56 & $4.2 \times 10^{-3}$ & - & $10.53^{d}$ & $3.7 \times 10^{14 e}$ \\
\hline
\end{tabular}

${ }^{a} \alpha=-\ln \left(N_{1} / N_{1}^{0}\right)$ for the Rayleigh model with constant flux $(f(t)=1)$; for the constant inventory model, $\alpha=$ $F_{\mathrm{l}}\left(t_{2}-t_{0}\right) / N_{1}$ for $f(t)=1, F_{1}^{0} k N_{1}$ for $f(t)=\exp \left[-k\left(t-t_{0}\right)\right]$, and $F_{1}^{0} t_{0} / N_{1}$ for $f(t)=\left(t_{0} / t\right)^{1.5}$.

${ }^{b} \Delta N_{1} / N_{1}=$ integrated hydrogen escape in units of the constant inventory $N_{\mathrm{t}}$.

${ }^{c}$ Hydrogen escape flux from Earth in $\mathrm{mol} / \mathrm{cm}^{2} / \mathrm{sec}$, from Eq. (16) with $T=400^{\circ} \mathrm{K}, b=2 \times 10^{19} \mathrm{~cm}^{-1} \mathrm{sec}^{-1}, X_{1}$

$=1$ and $g_{0}=980 \mathrm{~cm} / \mathrm{sec}^{2}$.

${ }^{d}$ Integrated hydrogen escape during decrease of the crossover mass from $m_{c}^{0}$ to $m_{c}=124 \mathrm{u}$.

e Initial hydrogen escape flux $F_{1}^{0}$ (Eq. (19)).

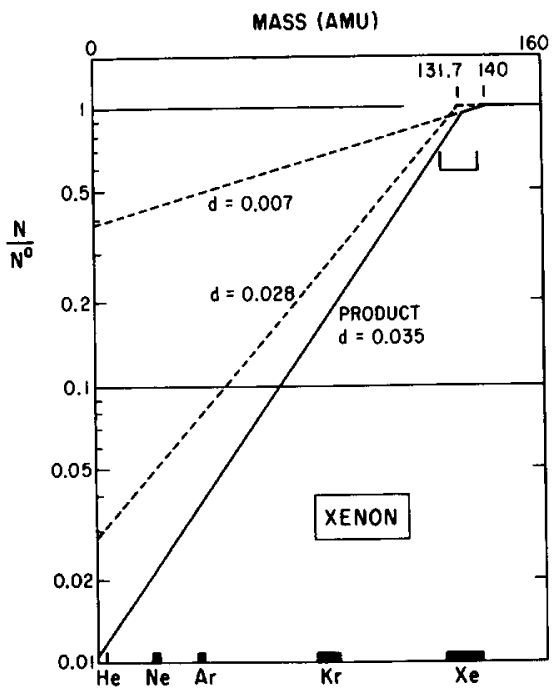

FIG. 5. The fractionation deduced for terrestrial xenon isotopes in Fig. 3 is extended to lower masses. Remaining fractions prediced for the light noble gases are a few percent. were retained within the solid phase of the planet in combined form, they would have suffered relatively less fractionation than the inert gas. The slope parameter $d=$ 0.035 , combined with a crossover mass of $140 \mathrm{amu}$, corresponds to the loss of all but a fraction 0.0087 of the initial hydrogen inventory in the Rayleigh fractionation model. In the model of constant hydrogen inventory with replenishment just balancing loss, the integrated loss is 4.75 times the inventory, $F_{1} t / N_{1}=4.75$. Earth's presentday inventory of hydrogen, mostly as water in the ocean, is $1.5 \times 10^{23} \mathrm{~g}$. The initial inventory in the Rayleigh fractionation model would have been $1.7 \times 10^{25} \mathrm{~g}$. This does not seem like an impossibly large amount, compared with the planetary mass of $6.0 \times 10^{27} \mathrm{~g}$. The initial inventory could have been much smaller if much of the present-day inventory of hydrogen was in chemically combined form in the solid 
phase rather than in the atmosphere. Then the hydrodynamic escape episode could have left the Earth with less hydrogen remaining in the atmosphere than is now present in the ocean. With this precautionary remark we can nevertheless calculate a characteristic duration for the escape episode. The initial hydrogen inventory calculated above corresponds to an abundance of $1.0 \times 10^{30}$ molecules of hydrogen per square centimeter. If this inventory is divided by the escape flux derived above, $F_{1}$ $=8.1 \times 10^{13} \mathrm{~mol} / \mathrm{cm}^{2} / \mathrm{sec}$, the resulting duration is $4.0 \times 10^{8}$ years. This is uncomfortably long compared with the time for decrease of the extreme ultraviolet flux from the Sun (Zahnle and Walker, 1982). Again it seems likely that the present-day ocean does not represent the remnant of terrestrial hydrogen not carried away in the hydrodynamic escape event.

As shown in Table $V$, flux and energy requirements for fractionation of $\mathrm{U}-\mathrm{Xe}$ in a constant flux model are very similar to those for AVCC-Xe. In the declining flux models needed to match more closely the Fig. 4 mass distribution, initial escape rates $F_{1}^{0}$ are up to $\sim 5$ times higher, and therefore so is the initial energy input required to drive the escape. The early history of the solar EUV flux suggested by Zahnle and Walker (1982) can be represented by $\phi$ $\propto(1 / t)^{s}$, where $t$ is the age of the Sun and 0.5 $\geq s \geq 1.5$. If we suppose that the hydrogen escape rate varied as a similar power of the time, then $F_{1}=F_{1}^{0} f(t) \sim F_{1}^{0}\left(t_{0} t\right)^{s}$. Time scales are given by Eq. (22): $f\left(t_{2}\right)=\left(m_{2}-\right.$ $\left.m_{1}\right) /\left(m_{\mathrm{c}}^{0}-m_{1}\right)=\left(t_{0} / t_{2}\right)^{s}$ which yields $t_{2}=t_{0}$ $\exp \left(-(1 / s) \ln \left[\left(m_{2}-m_{1}\right) /\left(m_{\mathrm{c}}^{0}-m_{1}\right)\right]\right)$. There are exact fits to the Fig. 4 data for $s \geq 1$, and for $s=1.5$ (at the upper end of Zahnle and Walker's exponent range) and $m_{\mathrm{c}}^{0}=625$ amu from Table $\mathrm{V}$, the duration of the xenon fractionation episode $\left(m_{2}=124 \mathrm{amu}\right)$ is $t_{2}=3.0 t_{0}$. If hydrogen escape continues for as long as $46 t_{0}$, the crossover mass has dropped to $4 \mathrm{amu}$ and at this point only $3 \times$ $10^{-9}$ of the original helium inventory is still present.
Estimation of $t_{0}$, the time when the escape episode began, depends very much on the assumed value for $s$, or $k$ if the early escape rate turns out to be exponential. It may be that the drop-off of EUV flux from the young Sun described by $s=1.5$ is too steep; as noted earlier, $s=\frac{5}{6}$ provides a reasonable fit to the observations from $10^{6}$ to $4 \times 10^{9}$ years. A hydrogen escape rate varying as $\left(t_{0} / t\right)^{5 / 6}$ also yields a reasonable fit (within $\sigma / 2$ ) to the mass distribution in Fig. 4 , for $m_{\mathrm{c}}^{0}=530 \mathrm{amu}$ and $\alpha=4.43$. In this case durations are longer, in units of $t_{0}: \mathrm{Xe}$ loss terminates at $5.8 t_{0}$, and $\mathrm{He}$ loss at $805 t_{0}$. At these times, $2 \%$ of the initial $\mathrm{Xe}$ and $2 \times 10^{-18}(!)$ of the initial He are retained. In Section 4 we calculated that with $\phi_{\mathrm{EUV}}=10^{8}(1 / t)^{5 / 6}$, the energy-limited crossover mass for Earth would be 225 amu at $10^{7}$ years. An initial crossover mass of 530 amu therefore requires a higher EUV flux than that at $10^{7}$ years by a factor $\sim 530 / 225$ $=2.36$. This occurs at $t=3.5 \times 10^{6}$ years. With this estimate for $t_{0}$, the xenon fractionation pattern is established in about 20 myr. Hydrogen inventory and integrated loss requirements are relatively modest. For an initial crossover mass of $530 \mathrm{amu}$, the initial hydrogen escape rate $F_{1}^{0}$ is $3.1 \times$ $10^{14} \mathrm{~mol} / \mathrm{cm}^{2} / \mathrm{sec}$. In this model, the constant hydrogen inventory $N_{1}$ is $F_{1}^{0} t_{0} / \alpha$, and with $t_{0}=3.5 \times 10^{6}$ years, $N_{1}$ is $7.7 \times 10^{27}$ $\mathrm{mol} / \mathrm{cm}^{2}$, about 25 bars or roughly one ocean equivalent of $\mathbf{H}_{2}$. Integrated hydrogen escape to the cessation of xenon loss is 9.0 times this amount.

There are of course large uncertainties in these calculations, since we do not know very well the form of the hydrogen escape flux versus time relationship, the value of $s$ if it is a power law, or the altitude $r$ of the escape level in Eq. (30). But they do illustrate the conditions under which xenon isotope fractionation in hydrodynamic escape could have been generated in a relatively short time early in the Earth's history.

Mars. As a second application of hydrodynamic escape to noble gas fractionation, we consider the data on relative noble gas 
concentrations in the atmosphere of Mars. Viking measurements are set out in Table III, and compared with analyses of gases trapped in the glassy lithology of the EETA 79001 shergottite. The striking similarity of the two data sets (which extends to isotopic compositions as well (Bogard and Johnson, 1983; Becker and Pepin, 1984; Wiens et al., 1986; Swindle et al., 1986)), together with other evidence (Wood and Ashwal, 1981; McSween, 1985), present a compelling case for the origin of EETA 79001 and the other SNC meteorites on Mars. In the following discussion we assume that the EETA 79001 glass data represent an unfractionated sample of trapped Martian atmosphere, and have used them, instead of the much less precise Viking data, in calculating the noble gas inventories for Mars shown in Table IV.

These inventories, normalized to ${ }^{130} \mathrm{Xe}$, are plotted in Fig. 6 relative to the corresponding abundance ratios in the Earth's atmosphere. Evidently Mars is depleted relative to the Earth in the lighter noble gases. For purposes of illustration we assume that the terrestrial values represent the initial inventories on Mars. We appreciate that this is not consistent with the analysis just presented of terrestrial xenon isotopes. The construction of scenarios that will reconcile data from diverse planets is a task for the future. At this point we are simply trying to illustrate the possible impact on planetary atmospheric evolution of hydrodynamic escape and the mass fractionation associated with it.

As shown in Fig. 6, a variety of the hydrodynamic escape models we have been considering can reproduce the observed mass distribution within the $1 \sigma$ errors. Parameters for the solutions plotted in Fig. 6 are listed in Table VI. The dotted line in this semilogarithmic plot represents the best fit to the data, just within the error bars, from the Rayleigh and constant inventory models with time-independent $(f(t)=$ 1) hydrogen escape flux. The mass distribution could therefore be a consequence of

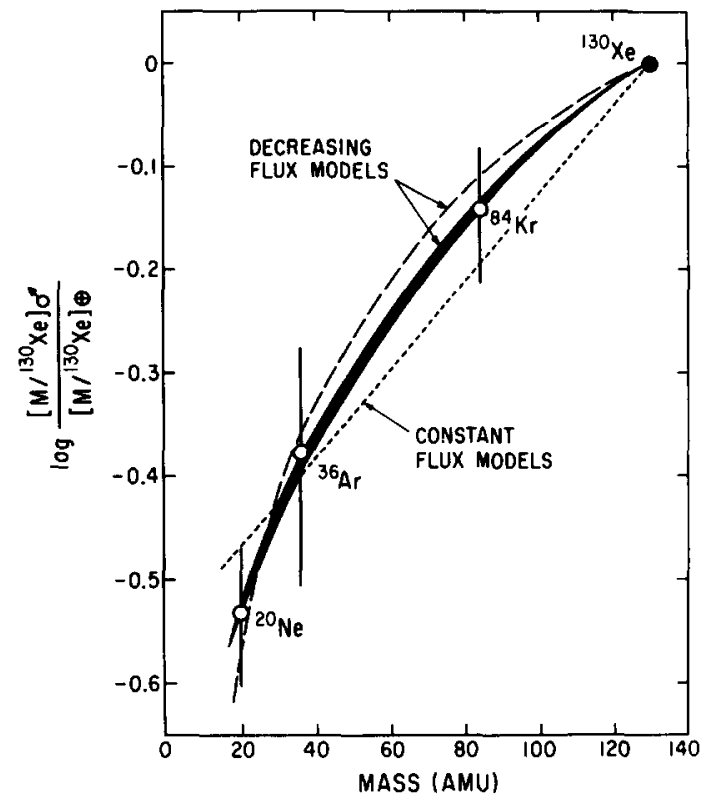

FIG. 6. Fractionation of noble gases on Mars assuming that terrestrial abundance ratios represent the initial inventories. Within the errors, the data may be interpreted in terms of either constant or declining flux models of hydrodynamic escape; the latter provide better fits to the concave downward curvature of the nominal mass distribution. The relative noble gas abundances are calculated from data in Table IV. The various models are identified and their parameters tabulated in Table VI.

hydrodynamic escape with a crossover mass $m_{\mathrm{c}} \geq 130 \mathrm{amu}$ and a slope parameter $d$ $=0.0098\left(d \equiv \alpha /\left(m_{\mathrm{c}}-m_{1}\right)\right.$ in Tables $\mathrm{V}$ and VI). From Table VI, a crossover mass of $130 \mathrm{amu}$ for Mars implies an escape flux $F_{1}$ of $2.9 \times 10^{13} \mathrm{~mol} / \mathrm{cm}^{2} / \mathrm{sec}$. The required energy flux is a modest $12 \mathrm{ergs} / \mathrm{cm}^{2} / \mathrm{sec}$. Integrated hydrogen loss $\Delta N_{1}$ is $1.26 N_{1}$ in the constant inventory model, or $0.72 N_{1}^{0}$ in the Rayleigh model. In these respects at least, the application to elemental fractionation on Mars appears much less demanding than the application to xenon isotope fractionation on Earth, because the Martian gravity is smaller and also because the data we are interpreting call for less fractionation.

Models of hydrodynamic escape with decreasing rather than constant hydrogen flux are better able to match the pronounced concave downward curvature of the Fig. 6 
TABLE VI

Parameter Values for Mass fractionation of Neon, Argon, and Krypton Relative to Xenon in Hydrodynamic Escape, from the Rayleigh and Constant Hydrogen INVENTORY Models with Constant Hydrogen Escape Flux, and from Both Models with Time-Dependent EsCAPE FLUX $F_{1}=F_{0}^{0} f(t)$

\begin{tabular}{lccccccc}
\hline Model & $f(t)$ & $m_{\mathrm{c}}^{0}$ & $\alpha^{a}$ & ${ }^{130} \mathrm{Xe} /(130 \mathrm{Xe})^{0}$ & $N_{1} / N_{1}^{0}$ & $\Delta N_{1} / N_{1}^{b}$ & $F_{1}^{c}$ \\
\hline $\begin{array}{c}\text { Rayleigh, } \\
\text { constant flux (Eq. (25)) }\end{array}$ & 1 & $\geq 130$ & $\geq 1.26$ & $\leq 1$ & $\leq 0.285$ & - & $\geq 2.9 \times 10^{13}$ \\
$\begin{array}{c}\text { Constant inventory, } \\
\text { constant flux (Eq. (23)) }\end{array}$ & 1 & $\geq 130$ & $\geq 1.26$ & $\leq 1$ & - & $\geq 1.26$ & $\geq 2.9 \times 10^{13}$ \\
$\begin{array}{c}\text { Constant inventory, } \\
\text { declining flux (Eq. (21)) }\end{array}$ & $e^{-k\left(t-t_{0}\right)}$ & 220 & 2.00 & 0.82 & - & $0.88^{d}$ & $4.9 \times 10^{13 e}$ \\
$\begin{array}{c}\text { Constant inventory, } \\
\text { declining flux (eq. (21)) }\end{array}$ & $\left(t_{0} / t\right)^{5 / 6}$ & 1400 & 0.35 & 0.47 & - & $2.91^{d}$ & $3.1 \times 10^{14 e}$ \\
$\begin{array}{c}\text { Constant inventory, } \\
\text { declining flux (Eq. (21)) }\end{array}$ & $\left(t_{0} / t\right)^{1.5}$ & 600 & 1.82 & 0.47 & - & $2.51^{d}$ & $1.3 \times 10^{14 e}$ \\
$\begin{array}{c}\text { Rayleigh, } \\
\text { declining flux (Eq. (27)) }\end{array}$ & $e^{-k\left(t-t_{0}\right)}$ & 1300 & 0.96 & 0.28 & $5.3 \times 10^{-2 f}$ & - & $2.9 \times 10^{14 e}$ \\
$\begin{array}{c}\text { Rayleigh, } \\
\text { declining flux (Eq. (27)) }\end{array}$ & $\left(t_{0} / t\right)^{2}$ & 2000 & 1.06 & 0.36 & $4.1 \times 10^{-2 f}$ & - & $4.5 \times 10^{14 e}$ \\
\hline
\end{tabular}

${ }^{a}$ For the Rayleigh model: $\alpha=-\ln \left(N_{1} / N_{1}^{0}\right.$ for $f(t)=1, F_{1}^{0} / k N_{1}^{0}$ for $f(t)=\exp \left[-k\left(t-t_{0}\right)\right]$, and $F_{1}^{0} t_{0} / N_{1}^{0}$ for $f(t)=$ $\left(t_{0} / t\right)^{2} ;$ for the constant inventory model: $\alpha=F_{1}\left(t_{2}-t_{0}\right) / N_{1}$ for $f(t)=1, F_{1}^{0} / k N_{1}$ for $f(t)=\exp \left[-k\left(t-t_{0}\right)\right]$, and $\left.F_{1}^{0} t_{0}\right]$ $N_{1}$ for $F(t)=\left(t_{0} / t\right)^{s}$.

${ }^{b} \Delta N_{1} / N_{1}=$ integrated hydrogen escape in units of the constant inventory $N_{1}$. $\mathrm{V}$.

${ }^{c}$ Hydrogen escape flux from Mars in $\mathrm{mol} / \mathrm{cm}^{2} / \mathrm{sec}$, from Eq. (16) with $g_{0}=373 \mathrm{~cm} / \mathrm{sec}^{2}$ and $T, b, X_{1}$ as in Table

${ }^{d}$ Integrated hydrogen escape during decrease of the crossover mass from $m_{\mathrm{c}}^{0}$ to $m_{\mathrm{c}}=20 \mathrm{u}$.

Initial hydrogen escape flux $F_{1}^{0}$ (Eq. (19)).

${ }^{f} N_{1} / N_{1}^{0}$ after decrease of the crossover mass from $m_{\mathrm{c}}^{0}$ to $m_{\mathrm{c}}=20 \mathrm{u}$.

mass distribution. The dashed curve in the figure represents solutions from Table VI with $f(t)=\left(t_{0} / t\right)^{s}$, for $s=\frac{5}{6}$ in the constant inventory model and for $s=2$, where Eqs. (27) can be integrated analytically, in the Rayleigh model. Solutions for the three remaining cases in Table VI fall within the solid curve in Fig. 6.

A problem now appears: the constant inventory model with a power law flux dependence of $s=\frac{5}{6}$ requires very long durations for the noble gas fractionation episode and enormous amounts of hydrogen. The energy-limited crossover mass for Mars is $1400 \mathrm{amu}$ at $t_{0}=8.4 \times 10^{6}$ years, from Eq. (30) with $\phi$ given by (31), where we have assumed that the EUV flux at Mars is reduced relative to Earth by $1 / 2.3$, the square of the orbital distance ratio. Duration of the escape episode through termination of neon loss, from Eq. (22) with $m_{2}=20 \mathrm{amu}$, is $t_{2}$ $=185 t_{0}$ or about $1.6 \times 10^{9}$ years using the above estimate for $t_{0}$. The inventory $N_{1}=$ $F_{1}^{0} t_{0} / \alpha$ is $2.4 \times 10^{29} \mathrm{~mol} / \mathrm{cm}^{2}$ or $\sim 300$ bars, equivalent to the hydrogen in $\sim 70 \mathrm{~km}$ of water. Losses are about three times greater. These results are unlikely to apply to Mars. There is morphologic evidence that a dense Martian atmosphere, if it ever existed, disappeared within $\sim 500-700 \mathrm{myr}$ (Schultz, 1986), and the total hydrogen required here significantly exceeds estimates, on the order of $90 \mathrm{~km} \mathrm{H} \mathrm{H}_{2} \mathrm{O}$ equivalent, for hydrogen incorporation into the planet during accretion (Dreibus and Wanke, 1985).

Large inventories and losses are common to all these models unless $t_{0}$ is very short. However, a solar EUV flux function as steep as $s=1.5$ (or a comparably steep exponential flux function) for some early 
period in the Sun's evolution could alleviate both the inventory and time scale problems somewhat. The constant inventory model with escape flux declining as $f(t)=$ $\left(t_{0} / t\right)^{1.5}$ fits both the Fig. 6 and Fig. 4 data well. Time to cessation of neon loss in this case, with $m_{\mathrm{c}}^{0}=600 \mathrm{amu}$, is $t_{2}=10.3 t_{0}$. The inventory $N_{1}$ is $2.3 \times 10^{21} t_{0}$ and the integrated hydrogen loss $\Delta N_{1}$ is $5.8 \times 10^{21} t_{0}$, in $\mathrm{mol} / \mathrm{cm}^{2}$ with $t_{0}$ in years. For an arbitrary choice of $t_{0}=10^{7}$ years, noble gas fractionation is established in 100 myr during loss of 71 bars of $\mathrm{H}_{2}$ from a hydrogen atmosphere maintained at a pressure of 29 bars. The time scale seems reasonable, but 100 bars is still a lot of hydrogen- $24 \mathrm{~km}$ of water would be needed to supply it.

These large numbers do not spring from anything fundamental; rather, they arise when an object having Mars' mass and position is subjected to early solar fluxes currently believed to be realistic. A flow with crossover mass only slightly greater than $m_{2}$ is inefficient in that the last parenthesis in (17) is very small; a large amount of hydrogen must be lost to carry away a small amount of heavy gas. The required quantities could be reduced by assuming a stronger Sun or by not assembling Mars from smaller bodies until the fractionation has taken place. Minimum loss of hydrogen is obtained by keeping the inventory only just large enough to make it a major constituent. As Table $\mathrm{V}$ shows, the Rayleigh model leaves a little under $1 \%$, and in a constant-inventory model the inventory must be replaced 5-10 times. The absolute quantities could still be fairly modest.

Nevertheless, the specific instances considered above strongly suggest that Mars was hydrogen rich early in its history, if hydrodynamic escape actually was responsible for fractionating an initially Earth-like abundance pattern of noble gases into the present distribution in its atmosphere.

\section{DEUTERIUM AND HELIUM}

Rapid escape of hydrogen from Venus has been modeled in an important paper by
Kasting and Pollack (1983). They found escape fluxes of $H$ ranging up to $2 \times 10^{11} \mathrm{~cm}^{-2}$ $\mathrm{sec}^{-1}$, limited both by the availability of hydrogen from $\mathrm{H}_{2} \mathrm{O}$ and by available thermal energy derived from solar ultraviolet radiation. With $g=850 \mathrm{~cm} \mathrm{sec}^{-2}, T=400^{\circ} \mathrm{K}$, and $b=2.2 \times 10^{19} \mathrm{~cm}^{-1} \mathrm{sec}^{-1}$, Eq. (16) gives a crossover mass of $1.35 \mathrm{amu}$, not enough to sweep away either $\mathrm{H}_{2}$ or deuterium. It is likely that a somewhat larger flux could be obtained by minor variation of the input parameters; for example, if the flux were an order of magnitude greater, the crossover mass would rise to 4.5 . Deuterium enrichment would still occur, just as in the examples of the previous section, but both isotopes would be escaping.

A question of long standing is the selective escape of hydrogen from a Jovian planet. Shklovski (1951), Opik (1963), and Hunten (1973) all concluded that significant separation of hydrogen from helium is impossible for an atmosphere whose mass is a substantial fraction of that of the planet. We are now in a position to make a more quantitative statement about the maximum size of an atmosphere that can be appreciably fractionated. Uranus is used as a specific example, because its $\mathrm{He} / \mathrm{H}_{2}$ ratio may be enhanced by a few percent relative to Jupiter. The very large value obtained by Orton (1986) is not supported by Voyager results (Hanel et al., 1986), but the latter still suggest an enrichment by a factor of 1.41 , so that $1+d=1.19$. We start with the simpler and more likely possibility, that hydrogen escapes but helium does not; $m_{\mathrm{c}}$ can be taken as 4 amu. With $m_{1}=2$ amu and $X_{1}$ $=0.9$, we find from Eq. (16) a maximum flux $F_{1}=10^{12} \mathrm{~cm}^{-2} \mathrm{sec}^{-1}$. Acting over the life of the Solar System, this flux would remove $1.4 \times 10^{29} \mathrm{~cm}^{-2}$ of $\mathrm{H}_{2}$ molecules, corresponding to a drop in partial pressure of 420 bars. The residual atmosphere could have partial pressures of 1000 bars of $\mathrm{H}_{2}$ and 370 bars of He. If the rapid escape occurred for a shorter period, these values should be scaled down in proportion.

Cases with $m_{\mathrm{c}}>4$ can be considered with the aid of Eq. (25); it turns out that the al- 
lowable atmospheric mass remains nearly constant as $m_{\mathrm{c}}$ begins to increase, and then drops. The example given above therefore gives the deepest possible fractionated atmosphere. An atmosphere of such depth is consistent with what we know about Uranus, although there is no reason to expect that hydrodynamic loss did actually take place. Moreover, the value of $1+d$ quoted above bears a large uncertainty, and the error estimates on the Voyager results for Jupiter and Uranus actually overlap.

Owen et al. (1986) have discussed the observed enrichment of $\mathrm{CH}_{3} \mathrm{D}$ relative to $\mathrm{CH}_{4}$ on Uranus; they conclude that it is a factor of 4.5 relative to the protosolar value. The most efficient way to obtain enrichment in a hydrodynamic flow would be to have the deuterium as HD, which would be enriched only by the factor 1.19 suggested above, far short of 4.5 . There would still be the issue of whether the deuterium could be equilibrated with the methane. Thus, hydrodynamic escape is very unlikely to have contributed a significant fraction of the enrichment.

\section{DISCUSSION}

We have not dealt in this paper with the conditions that would cause large hydrodynamic escape fluxes from the inner planets. Our goal has been to show that hydrodynamic escape, if it occurred, could have yielded substantial mass fractionation. Whether we deal with a Rayleigh fractionation model, in which all of the planet's hydrogen is initially in the atmosphere and the hydrogen inventory decreases along with the inventories of heavier gases, or a model of constant replenishment of the hydrogen, hydrodynamic escape yields a mass distribution with a constant slope or concave downward curvature in a plot of the logarithm of abundance against mass. In other words, the fractionation is a strong function of mass, but not nearly as sensitive to mass as is the fractionation in Jeans escape. Therefore, mass fractionation in hydrodynamic escape yields results that are compa- rable to observed mass distributions on various planets. Here we have presented several illustrative applications. We have made no attempt to make these applications mutually consistent. The task of developing a general theory of the evolution of planetary atmospheres with a single scenario that will reconcile a wide range of planetary data remains for the future. Our goal in this paper has been to argue that such a future synthesis would do well to include consideration of the potential role of mass fractionation in hydrodynamic escape.

\section{ACKNOWLEDGMENTS}

Some of this research is an outgrowth of presentations and discussions at the LPI Workshop on the Evolution of the Martian Atmosphere held in Honolulu on August 9 and 10, 1985. The work at the University of Michigan was supported in part by Nasa Grant NAS2-9126, at the University of Arizona by NASA Grant NSG-7558, and at the University of Minnesota by NASA Grant NAG 9-60.

\section{REFERENCES}

Becker, R. H., AND R. O. PePIN (1984). The case for a Martian origin of the shergottites: Nitrogen and noble gases in EETA 79001. Earth Planet. Sci. Lett. 69, 225-242.

Bogard, D. D., AND P. Johnson (1983). Martian gases in an Antarctic meteorite? Science 221, 651654.

Bogard, D. D., L. E. Nyquist, and P. Johnson (1984). Noble gas contents of shergottites and implications for the Martian origin of SNC meteorites. Geochim. Cosmochim. Acta 48, 1723-1739.

Canuto, V. M., J. S. Levine, T. R. Augustsson, AND C. L. IMHOFF (1982). UV radiation from the young Sun and oxygen and ozone levels in the prebiological palaeoatmosphere. Nature 296, 816-820.

Chamberlain, J. W., and D. M. Hunten (1986). Theory of Planetary Atmospheres, 2nd ed. Academic Press, New York.

Chapman, S., And T. G. Cowling (1970). The Mathematical Theory of Non-Uniform Gases, 3rd ed. Cambridge Univ. Press, Cambridge.

Donahue, T. M. (1986). Thermal escape from accreting planetesimals. Icarus 66, 195-210.

Dreibus, G., AND H. Wanke (1985). Mars, a volatilerich planet. Meteoritics 20, 367-381.

GeIss, J. (1982). Processes affecting abundances in the solar wind. Space Sci. Rev. 33, 201-217.

Geiss, J., P. Hirt, ANd H. Leutwyler (1970). On acceleration and motion of ions in corona and solar wind. Sol. Phys. 12, 458-483. 
Hanel, R. A., B. Conrath, F. M. Flasar, V. Kunde, W. Maguire, J. Pearl, J. Pirraglia, AND R. SAMUELSON (1986). .Infrared observations of the Uranian system. Science 233, 70-74.

Hunten, D. M. (1973). The escape of light gases from planetary atmospheres. J. Atmos. Sci. 30, 14811494.

Hunten, D. M. (1979). Capture of Phobos and Deimos by protoatmospheric drag. Icarus 37, 113-123.

Hunten, D. M. (1982). Thermal and nonthermal escape mechanisms for terrestrial bodies. Planet. Space Sci. 30, 773-783.

Hunten, D. M. (1985). Blowoff of an atmosphere and possible application to Io. Geophys. Res. Lett. 12 , 271-273.

Joselyn, J., AND T. E. Holzer (1978). A steady three-fluid coronal expansion for nonspherical geometries. J. Geophys. Res. 83, 1019-1026.

Kasting, J. F., AND J. B. Pollack (1983). Loss of water from Venus. 1. Hydrodynamic escape of hydrogen. Icarus 53, 479-508.

Krummenacher, D., C. M. Marrihue, R. O. Pepin, AND J. H. REYNOLDS (1962). Meteoritic krypton and barium versus the general isotopic anomalies in xenon. Geochim. Cosmochim. Acta. 26, 231-249.

McSweEn, H. Y., JR. (1985). SNC meteorites: Clues to Martian petrologic evolution? Rev. Geophys. 23, 391-416.

Nier, A. O., AND M. B. McElroy (1977). Composition and structure of Mars' upper atmosphere: results from the neutral mass spectrometers on $\mathrm{Vi}$ king 1 and 2. J. Geophys. Res. 82, 4341-4349.

OPIK, E. J. (1963). Selective escape of gases. Geophys. J. R. Astron. Soc. 7, 490-509.

ORTON, G. S. (1986). Thermal spectrum of Uranus: Implications for large helium abundance. Science 231, 836-840.

Owen, T. C., K. Biemann, D. R. Rushneck, J. E. Biller, D. W. Howarth, and A. L. Lafleur (1977). The composition of the atmosphere at the surface of Mars. J. Geophys. Res. 82, 4635-4639.

Owen, T. C., B. L. Lutz, C. De BerGH (1986). Deuterium in the outer Solar System: Evidence for two distinct reservoirs. Nature 320, 244-246.

Pepin, R. O., ANd D. Phinney $(1978,1986)$. Compo- nents of xenon in the Solar System. Earth Moon Planets, in press.

Pollack, J. B., AND D. C. Black (1982). Noble gases in planetary atmospheres: Implications for the origin and evolution of atmospheres. Icarus 51, 169-198.

RAYLEIGH, LORD (1895). Theoretical considerations respecting the separation of gases by diffusion and similar processes. Philos. Mag. 42, 493-498.

Schultz, P. H. (1986). The Martian Atmosphere before and after the Argyre Impact, pp. 38-39. LPI Technical Report 86-07, The Lunar and Planetary Institute, Houston, TX.

SHKLovSkI, I. S. (1951). On the possibility of explaining the difference in chemical composition of the Earth and Sun by thermal dissipation of light gases. Astron. Zh. 28, 234-243.

Swindle, T. D., M. W. Caffee, and C. M. HohenBERG (1986). Xenon and other noble gases in shergottites. Geochim. Cosmochim. Acta 50, 10011015.

WAlker, J. C. G. (1977). Evolution of the Atmosphere. Macmillan, New York.

WALKER, J. C. G. (1982). The earliest atmosphere of the Earth. Precambrian Res. 17, 147-171.

Watson, A. J., T. M. Donahue, and J. C. G. WALKER (1981). The dynamics of a rapidly escaping atmosphere: Applications to the evolution of Earth and Venus. Icarus 48, 150-166.

Wiens, R. C., R. H. Becker, AND R. O. Pepin (1986). The case for Martian origin of the shergottites. II. Trapped and indigenous gas components in EETA 79001 glass. Earth Planet. Sci. Lett. 77, 149-158.

Wood, C. A., AND L. D. Ashwal (1981). SNC meteorites: Igneous rocks from Mars? Proc. Lunar Planet. Sci. Conf. I2th, 1359-1375.

Wright, I. P., R. H. Carr, and C. T. Pillinger (1986). Carbon abundance and isotopic studies of Shergotty and other shergottite meteorites. Geochim. Cosmochim. Acta. 50, 983-991.

ZAHNLE, K. J., AND J. F. KAsting (1986). Mass fractionation during transonic hydrodynamic escape and implications for loss of water from Venus and Mars. Icarus 68, 462-480.

Zahnle, K. J., ANd J. C. G. Walker (1982). The evolution of solar ultraviolet luminosity. Rev. Geophys. Space Phys. 20, 280-292. 